\title{
How to identify groundwater-caused thermal anomalies in lakes based on multi-temporal satellite data in semi-arid regions
}

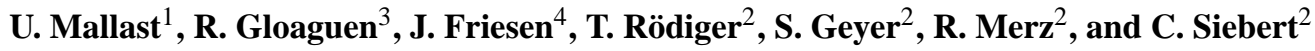 \\ ${ }^{1}$ Helmholtz Centre for Environmental Research, Department Groundwater Remediation, 06120 Halle, Germany \\ ${ }^{2}$ Helmholtz Centre for Environmental Research, Department Catchment Hydrology, 06120 Halle, Germany \\ ${ }^{3}$ Helmholtz Institute Freiberg of Resource Technology, Remote Sensing Group, 09599 Freiberg, Germany \\ ${ }^{4}$ Helmholtz Centre for Environmental Research, Department Computational Hydrosystems, 04318 Leipzig, Germany \\ Correspondence to: U. Mallast (ulf.mallast@ufz.de)
}

Received: 13 February 2013 - Published in Hydrol. Earth Syst. Sci. Discuss.: 18 April 2013

Revised: 18 June 2014 - Accepted: 20 June 2014 - Published: 31 July 2014

\begin{abstract}
The deduction by conventional means of qualitative and quantitative information about groundwater discharge into lakes is complicated. Nevertheless, at least for semi-arid regions with limited surface water availability, this information is crucial to ensure future water availability for drinking and irrigation purposes.

Overcoming this lack of discharge information, we present a satellite-based multi-temporal sea-surface-temperature (SST) approach. It exploits the occurrence of thermal anomalies to outline groundwater discharge locations using the example of the Dead Sea. Based on a set of 19 Landsat Enhanced Thematic Mapper (ETM+) images 6.2 (high gain), recorded between 2000 and 2002, we developed a novel approach which includes (i) an objective exclusion of surfacerunoff-influenced data which would otherwise lead to erroneous results and (ii) a temporal SST variability analysis based on six statistical measures amplifying thermal anomalies caused by groundwater.

After excluding data influenced by surface runoff, we concluded that spatial anomaly patterns of the standard deviation and range of the SST data series spatially fit best to in situ observed discharge locations and, hence, are most suitable for detecting groundwater discharge sites.
\end{abstract}

\section{Introduction}

The deduction of qualitative and quantitative information on groundwater discharge is complicated since direct measurements over large temporal and spatial scales by conventional means are difficult to pursue (IAEA, 2007). This deduction would allow an improvement on sustainable management strategies and also a direct facilitation of a smart usage prior to the loss of groundwater to saline water bodies (Maimone, 2004). Particularly in semi-arid regions with limited surface water availability this information is essential to ensure future water availability for drinking and irrigation purposes.

For the spatial scale, thermal remote sensing offers an opportunity to identify discharge locations. The principle is based on sea surface temperature (SST) differences in the uppermost layer (skin layer) of the investigated water body (Donlon et al., 2002; Emery et al., 2001). These differences are caused by atmospheric, bathymetric, anthropogenic, or hydrologic (surface and groundwater discharge) processes and result in different patterns, varying in space and time.

Atmospheric effects on lakes display a sinusoidal SST course which reflects the seasonal variability of air temperature (Nehorai et al., 2009; Wloczyk et al., 2006). The evoked spatio-temporal SST pattern is similar for the entire water body and can be homogeneous in the case of a water body with uniformly distributed depth. With varying depths and complex bathymetry, SST patterns become more heterogeneous. Deeper and mostly distal parts show a temporal SST pattern that generally behaves analogously to air temperature whereas the larger water column buffers seasonal temperature extremes. In contrast, in shallow areas SST follows the temperature extremes since smaller water columns possess less capacity to buffer temperature fluctuations and, hence, show a general heating (cooling) of these areas in summer (winter) (Baban, 1993). 
This homogeneity can be disturbed by local thermal anomalies caused by e.g. surface runoff (Arnau et al., 2004; Piñones et al., 2005; Walker, 1996) and groundwater inflow (Banks et al., 1996; Danielescu et al., 2009). In semi-arid areas surface runoff occurs as ephemeral flash flood during rainy periods. Long-term considerations reveal that the local thermal anomalies caused in this way exhibit a high SST variability ranging from low SSTs during winter to high SSTs during summer when no flash floods eventuate. In contrast, groundwater-caused thermal anomalies remain constant in space and time as the continuously discharging, relatively temperature-stable groundwater thermally stabilises a certain area off the discharge outlet (thermal anomaly).

While it appears that, based on these assumptions multitemporal SST pattern analysis can reveal groundwatercaused thermal anomalies, the primary problem arising within this context relates to the influence of surface runoff. If surface runoff occurs spatially at the same location as groundwater discharge, the resulting anomaly will be superimposed on the groundwater-caused anomaly.

Satellite-borne thermal remote sensing provides the required characteristic of repeated recording of the same location (Sentlinger et al., 2008) at defined intervals (several times per day to several days) with a large spatial coverage (typical swath widths range from a few to several hundred kilometres). Developing an objective approach which allows differentiating between thermal anomalies caused by groundwater and those caused by surface runoff is the first and most important objective of the present study. The fulfilment of this first objective and the consideration of the temporal influence of secondary processes (time-delayed drainage of bank infiltration from alluvial fans) overcome the subjectivity of previous approaches in the literature and, moreover, include the aspect of transferability to other semi-arid regions.

The second objective of this study relates to the assumption that thermal anomalies caused by groundwater reflect a smaller SST variability over time. To test this assumption we compare in situ observations with the performance of different statistical measures elucidating SST variability over time within a multi-temporal thermal satellite data framework. The result indicates the best-suitable measure and identifies thermal anomalies that are exclusively related to groundwater discharge.

Both objectives are addressed when investigating the exemplary case of the Dead Sea, as it offers different spring types (terrestrial and submarine), spring discharge characteristics (diffuse and concentrated), and ephemeral flash-flood events which are typical for semi-arid regions.

\section{Study area and groundwater inflow}

The Dead Sea (DS) is a terminal lake with a currently holomictic regime situated in the Jordan-Dead Sea Graben (Gertman and Hecht, 2002). Along its western shore, groundwater originates mainly from the Upper Cretaceous Judea Group, composed of limestone and dolomite. On its passage to the DS, groundwater flows through a Quaternary alluvial and lacustrine coastal sediment body that has partly fallen dry and that was deposited by the Dead Sea and its precursors (Yechieli et al., 2010; Mallast et al., 2011). From here, it preferentially discharges in spring areas such as Ein Feshkha, Kane/Samar, Qedem, and Ein Gedi (Fig. 1a and $b$ ) with accumulated amounts of $80-150 \times 10^{6} \mathrm{~m}^{3} \mathrm{a}^{-1}$ (Guttman, 2000; Laronne Ben-Itzhak and Gvirtzman, 2005; Lensky et al., 2005). In general two spring types occur: (i) terrestrial springs emerging along faults or sediment heterogeneities, forming erosion channels due to the lowering of the DS of currently $\sim 1 \mathrm{~m} \mathrm{a}^{-1}$ (Fig. 1c) (Lensky et al., 2005) and (ii) submarine springs that emerge on the lake's bottom down to observed depths of $30 \mathrm{~m}$ (Ionescu et al., 2012). After emerging from the lake bottom, a density-driven upward (jet) flow establishes itself. It results in the formation of a circular pattern at the DS surface (Munwes et al., 2010) (Fig. 1c).

Surface water inputs are limited to the perennial Jordan River discharging 250-300 $\times 10^{6} \mathrm{~m}^{3} \mathrm{a}^{-1}$ (Salameh, 1996) from the north and ephemeral flash floods generated after significant rainstorms in the rainy season (October-April) (Gertman and Hecht, 2002). The mean annual discharge amounts to $58-66 \times 10^{6} \mathrm{~m}^{3} \mathrm{a}^{-1}$ (Siebert et al., 2014), with flood volumes of $1-30 \times 10^{6} \mathrm{~m}^{3}$ and flow durations of 2$153 \mathrm{~h}$ (Greenbaum et al., 2006).

Rainstorms generating flash floods show temperatures of $10-15^{\circ} \mathrm{C}$ (Ayalon et al., 1998), which increase by $\sim 10^{\circ} \mathrm{C}$ until reaching the aquifers. This corresponds to groundwater temperatures in Ein Feshkha, Kane/Samar, and Ein Gedi of $25-28^{\circ} \mathrm{C}$ throughout the year (Mazor et al., 1980; Siebert et al., 2013). In certain places, such as Qedem and Mineral Beach, groundwater is partly heated by ascending brines (Stanislavsky and Gvirtzman, 1999). In contrast, the skin temperature of the DS varies dynamically between $23^{\circ} \mathrm{C}$ during winter (December-March) and $30^{\circ} \mathrm{C}$ during summer (June-October). The maximum of $>34^{\circ} \mathrm{C}$ is reached in August/September (Gertman and Hecht, 2002). Particularly in summer, the thermal gradient between cool groundwater and warm DS water shows promise for thermal analysis of groundwater inflow (Table 1). This fact is even enhanced as fresh to brackish groundwater (density of $1.06-1.19 \mathrm{~g} \mathrm{~cm}^{-3}$ ) ascends to the skin surface of the DS due to the latter's high density of $1.24 \mathrm{~g} \mathrm{~cm}^{-3}$ (Gavrieli et al., 2001). 

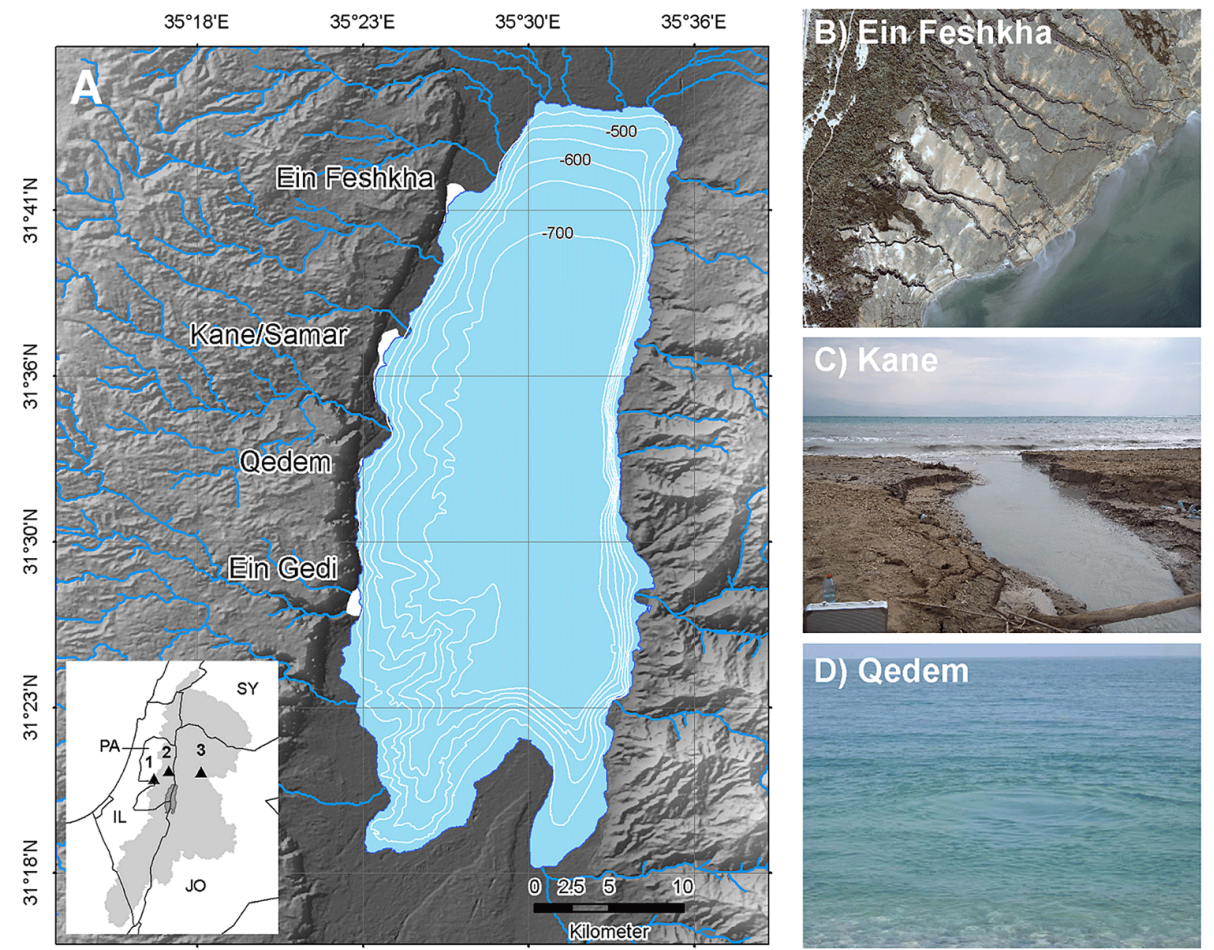

Figure 1. (A) Study area overview. Map: blue area represents DS in the year 2000; small white areas represent spring areas (Ein Feshkha/Kane/Qedem/Ein Gedi); solid blue lines indicate wadis and river courses; solid white lines indicate $50 \mathrm{~m}$ contour lines of the bathymetry following (Hall, 1979). Inset: grey coloured area represents catchment of the DS; numbers indicate names of meteorological stations $(1=$ Jerusalem, 2 = Gilgal, 3 =Amman). Abbreviations: IL: Israel; PA: Palestinian Authority; JO: Jordan; SY: Syria). Pictures: all illustrate spring types representative of the study area; (B) shows an aerial photograph of the northern Ein Feshkha area from January 2011 with several erosion channels discharging into the DS; (C) shows a similar erosion channel of a terrestrial spring located upstream in the Kane area and (D) shows a submarine spring in the Qedem area (source of picture D: Munwes et al., 2010).

\section{Data and pre-processing}

19 Landsat ETM+ band 6.2 (high-gain) images (path 174/row 38) recorded between 2000 and 2002 with a cloud cover of less than $15 \%$ are analysed (Sect. S1 in the Supplement). All data is recorded at approximately 10:00 LT $(\mathrm{GMT}+2)$ and georeferenced to UTM WGS 84 Zone $36 \mathrm{~N}$. To exclude land pixels, we used a threshold of -0.1 of the Normalized Difference Water Index (NDWI)-derived image, using ETM+ band 4 and 2 (see Sect. 4.1 for details) from the earliest image of the series (15 February 2000).

Pre-processing consists of several steps to investigate true SST differences. We reconverted raw space-borne digital numbers $(\mathrm{DN})$ which reflect converted thermal radiances in the spectral wavelength of $10.4-12.5 \mu \mathrm{m}$ to radiances at the top of the atmosphere $\left(L_{\mathrm{TOA}}\right)$ using Eq. (1):

$L_{\mathrm{TOA}}=c_{0}+c_{1} \mathrm{DN}$,

where $c_{0}$ (offset) and $c_{1}$ (gain) are the radiometric calibration coefficients according to Chander et al. (2009) and DN are satellite-based digital numbers between 0 and 255 .

$L_{\mathrm{TOA}}$ consists of thermal radiation leaving the surface and thermal radiation emitted by the atmosphere. To account for
Table 1. Temperatures of important waters influencing the thermal pattern of the DS.

\begin{tabular}{lll}
\hline $\begin{array}{l}\text { Water } \\
\text { source }\end{array}$ & $\begin{array}{l}\text { Temperature } \\
{\left[{ }^{\circ} \mathrm{C}\right]}\end{array}$ & Source \\
\hline $\begin{array}{l}\text { Surface water } \\
\text { Groundwater }\end{array}$ & $\begin{array}{l}10-15 \\
25-28\end{array}$ & $\begin{array}{l}\text { Ayalon et al. (1998) } \\
\text { Mazor et al. (1980), } \\
\text { Diebert et al. (2013) }\end{array}$ \\
Dead Sea & $23-34^{*}$ & Gertman and Hecht (2002) \\
\hline
\end{tabular}

* Lower value represents an average winter temperature, while higher value represents average summer temperature.

attenuation of both through the atmosphere itself, we need to integrate a radiative transfer model (Barsi et al., 2005) to obtain transmission, and upwelling and downwelling radiance values. Integrating those values, we can solve for surface radiances of an ideal blackbody $\left(L_{T}\right)$ :

$L_{T}=\frac{L_{\mathrm{TOA}}-L_{\mathrm{U}}-\tau(1-\varepsilon) L_{\mathrm{D}}}{\tau \varepsilon}$,

where $\varepsilon$ is surface emissivity; $\tau$ is atmospheric transmissivity; $L_{\mathrm{U}}$ represent upwelling radiances and $L_{\mathrm{D}}$ represent 
downwelling radiances all for the specific site and time of the respective image.

As we focus on water we apply an emissivity value of 0.97 , being aware of the fact that Salisbury and D'Aria (1992) had stated water emissivity to vary between 0.97 and 0.99 in the 8-14 $\mu \mathrm{m}$ region. However, as the DS water contains salt concentrations of $\sim 300 \mathrm{~g} \mathrm{~L}^{-1}$, we follow Wenyao et al. (1987), who found a lower value of around 0.97 at higher salinities $(>34 \%)$.

To convert $L_{T}$ to surface temperatures $(T)$, we adapt Planck's radiation law using two pre-launch calibration constants. Solving for SST in degree Celsius yields

$\operatorname{SST}\left({ }^{\circ} \mathrm{C}\right)=\frac{k_{2}}{\ln \left(\frac{k_{1}}{L_{T}}+1\right)}$,

where $k_{1}$ is the calibration constant equal to $666.09 \mathrm{~W} \mathrm{~m}^{-2} \mathrm{sr}^{-1} \mu \mathrm{m}^{-1}$ ) and $k_{2}$ is the calibration constant equal to $1282.71 \mathrm{~K}$ following Chander et al. (2009) for $\mathrm{ETM}+$ data.

According to Barsi et al. (2005), the error of temperature approximation is less than $0.5 \pm 0.8 \mathrm{~K}$ for the temperature range of $270-330 \mathrm{~K}$. This error indicates the temperature difference due to the application of Planck's radiation law. The absolute error for the present study of the DS is presumably higher since the increased atmosphere of $\sim 400 \mathrm{~m}$ could not be included in the MODTRAN (MODerate resolution atmospheric TRANsmission) standard atmospheres (Barsi et al., 2005).

By using Eq. (3), the skin SST ( $\leq 1 \mathrm{~mm}$ of the uppermost water layer) is calculated. It is about $0.1 \mathrm{~K}$ colder than lower water masses due to evaporative heat loss, sensible heat flux, and long-wave radiation (Wloczyk et al., 2006). For a complete analysis of skin-bulk effects, see Donlon et al. (2002).

Besides satellite data, rainfall data - rain occurrence (date), rain intensity ( $\mathrm{mm}$ ), event duration (d), and accumulated rainfall per event $(\mathrm{mm})$ - for the period 2000-2002 are stored in a database using information from three stations: Gilgal (Lat 32.00, Lon 35.45), Jerusalem (Lat 31.87, Lon 35.22), and Amman (Lat 31.98, Lon 35.98) (Fig. 1). Gilgal belongs to the Israel Meteorological Service while data for the latter two is acquired from Metbroker (http: //pc105.narc.affrc.go.jp/metbroker). Since these rainfall stations cover only the northern part of the DS catchment, we also include daily rain intensities $(\mathrm{mm})$ from Tropical Rainfall Measuring Mission TRMM_3B42 data for completeness (Sect. S2-5 in the Supplement). The TRMM_3B42 product used covers the period from January 2000 to December 2002 with a 3-hourly interval and a spatial resolution of $0.25^{\circ}$ (Huffman et al., 2007).

To verify and evaluate inferred groundwater discharge locations, in situ groundwater discharge measurements, which were recorded in March 2008 by the Israel Hydrological Service (IHS), are available.

\section{Groundwater-surface water influx separation}

The previously proposed direct influence of surface runoff and time-delayed drainage of bank infiltration from alluvial fan gravel on the SST pattern appears in several Landsatconverted SST data in the form of discharge plume structures (white areas in Fig. 2).

As surface runoff flows into the DS, two processes take place: (i) within an area close to wadi outlets, the SST pattern of the DS is locally influenced and the SST is lowered as absolute temperatures of surface runoff $\left(\sim 15^{\circ} \mathrm{C}\right)$ are steadily below both the long-term minimum DS temperature $\left(23^{\circ} \mathrm{C}\right)$ and the coldest measured DS temperature of $16-17^{\circ} \mathrm{C}$ in February 1992 (Ayalon et al., 1998; Gertman and Hecht, 2002); (ii) inflowing water loses an enormous amount of kinetic energy as it impinges in the standing water body of the DS. Particularly the latter process leads to a spatial limitation of the temperature influence on near-shore areas, while central parts of the DS remain less influenced at all times.

Findings of Stanhill (1990) and Nehorai et al. (2009) support the minor influence on central parts. Both reported a maximum range of $2.5^{\circ} \mathrm{C}$ in the central lake area while our own investigation shows steady SST standard deviation values between 0.2 and $0.4^{\circ} \mathrm{C}$. In contrast, at outlets, SST standard deviation values rise up to $6^{\circ} \mathrm{C}$. Although, SST differences between wadi outlets and the DS central area are demonstrably appropriate for indicating surface runoff influence, two constraints need to be considered.

On the one hand, one constraint relates to the specificity of the DS with an average water level drop of $\sim 1 \mathrm{~m}$ per year, which results in a continuous retreat of the DS shoreline and the exposition of sediment areas differing in heat capacity from water. This characteristic would lead to higher global maximum temperatures of the SST image and therefore to an erroneous integration of land temperatures. On the other hand, we need to account for seasonal temperature variations that hinder comparing data over an intra- or inter-seasonal basis.

\subsection{Methodical pre-processing}

Accounting for both constraints and exploiting the SST differences, we introduce methodological pre-processing (Fig. 3). With regard to the retreating shoreline, we define the land-water interface individually per image using the Normalized Difference Water Index (NDWI) of McFeeters (1996) (Eq. 4). As a threshold, we apply a value of -0.1 , where values below the threshold represent water features:

$\mathrm{NDWI}=\frac{\text { Band4 }- \text { Band2 }}{\text { Band4 }+ \text { Band2 }}$

where Band 2 is the green band of Landsat ETM+ and Band4 is the Near-infrared (NIR) band of Landsat ETM+. 


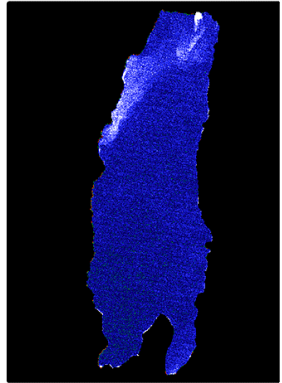

RD: $\quad 15.02 .2000$

TD: 1 day

Ml: $\quad 47.5 \mathrm{~mm}(J)$

$\mathrm{IF}_{\min }:-0.104$

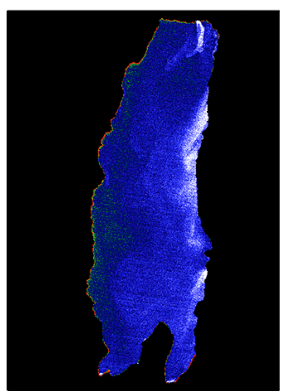

$\mathrm{RD}: \quad 28.10 .2000$

TD: 2 days

$\mathrm{Ml}: \quad 7.2 \mathrm{~mm}(\mathrm{~A})$

$\mathrm{IF}_{\min }:-0.135$

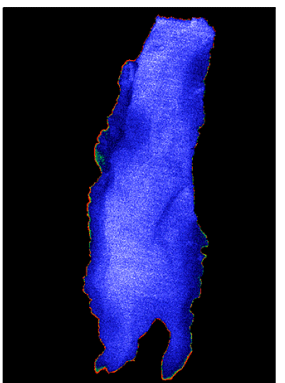

TD: 5 days

$\mathrm{IF}_{\min }: 0.019$

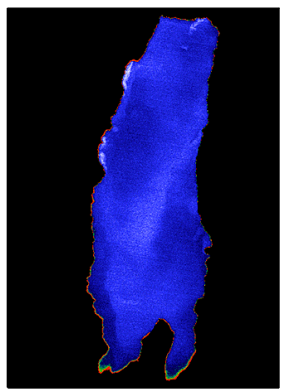

RD: $\quad 11.07 .2001$

TD: 45 days

MI: $\quad 50 \mathrm{~mm}(\mathrm{~A})$

$\mathrm{IF}_{\text {min }}: 0.007$
RD: 21.03.2001

MI: $\quad 1 \mathrm{~mm}(\mathrm{~T})$

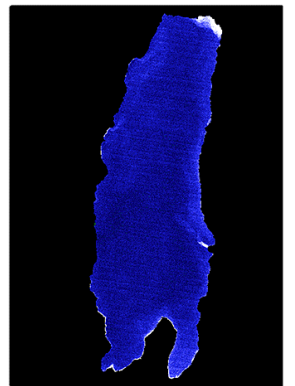

RD: $\quad 31.12 .2000$

TD: 1 day

Ml: $3 \mathrm{~mm}(\mathrm{~T})$

$\mathrm{IF}_{\min }:-0.318$

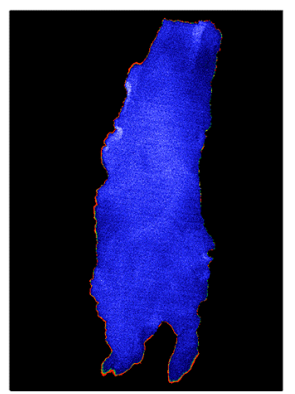

RD: 24.03.2002

TD: 2 days

Ml: $2 \mathrm{~mm}(\mathrm{~T})$

$\mathrm{IF}_{\text {min }}:-0.013$

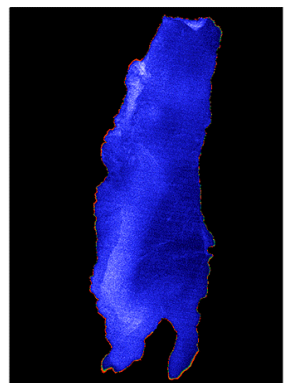

RD: 24.05.2001

TD: 7 days

MI: $\quad 1 \mathrm{~mm}(\mathrm{~T})$

$\mathrm{IF}_{\min }:-0.019$

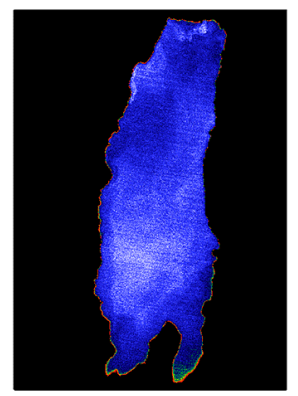

RD: $\quad 22.06 .2000$

TD: 49 days

Ml: $\quad 0.8 \mathrm{~mm}(\mathrm{~A})$

$\mathrm{IF}_{\min }: 0.018$

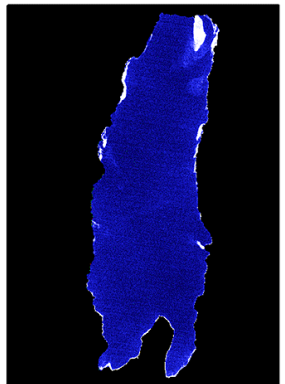

RD: 19.01.2002

TD: 1 day

Ml: $1 \mathrm{~mm}(\mathrm{~T})$

$\mathrm{IF}_{\text {min }}:-0.149$

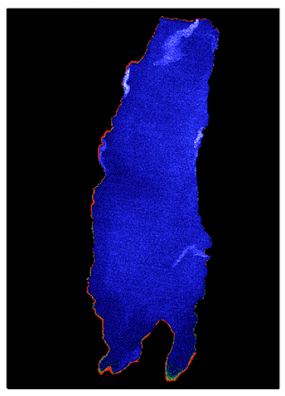

RD: $\quad 18.10 .2002$

TD: 2 days

MI: $\quad 10 \mathrm{~mm}(\mathrm{~T})$

$\mathrm{IF}_{\text {min }}:-0.062$

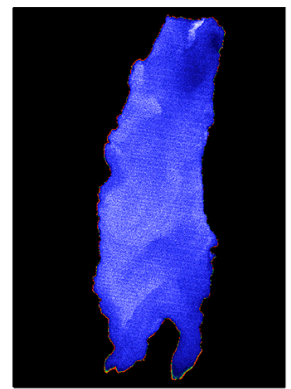

RD: $\quad 21.05 .2000$

TD: 17 days

MI: $0.8 \mathrm{~mm}(\mathrm{~A})$

$\mathrm{IF}_{\text {min }}: 0.006$

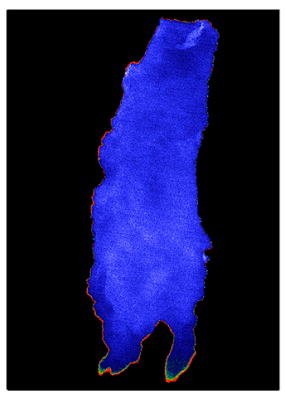

RD: 14.07 .2002

TD: 60 days

MI: $2 \mathrm{~mm}(\mathrm{G})$

$\mathrm{IF}_{\min }: 0.012$

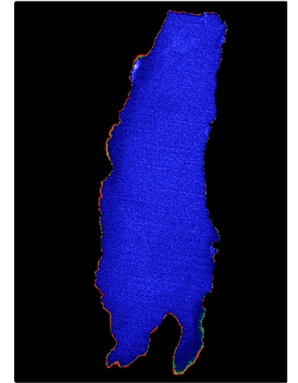

RD: $\quad 08.03 .2002$

TD: 1 day

MI: $\quad 5 \mathrm{~mm}(\mathrm{~T})$

$I \mathrm{~F}_{\text {min }}: 0.020$

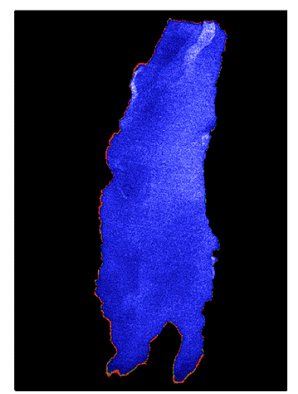

RD: $\quad 09.04 .2002$

TD: 3 days

MI: $2 \mathrm{~mm}(\mathrm{~T})$

$\mathrm{IF}_{\text {min }}:-0.020$

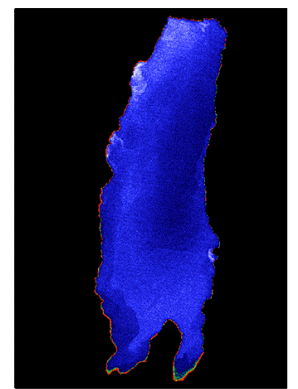

RD: $\quad 25.06 .2001$

TD: 29 days

MI: $\quad 50 \mathrm{~mm}(\mathrm{~A})$

$\mathrm{IF}_{\text {min }}:-0.076$

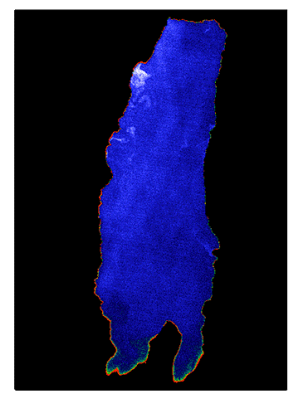

RD: $\quad 13.09 .2001$

TD: 109 days

MI: $\quad 50 \mathrm{~mm}(\mathrm{~A})$

$\mathrm{IF}_{\min }:-0.040$

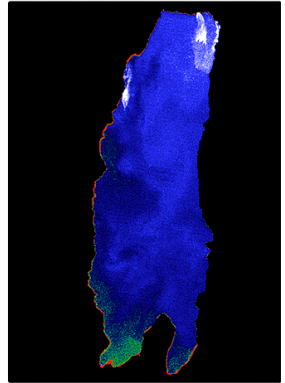

RD: $\quad 19.11 .2002$

TD: 1 day

MI: $2 \mathrm{~mm}(\mathrm{~T})$

$\mathrm{IF}_{\min }:-0.136$

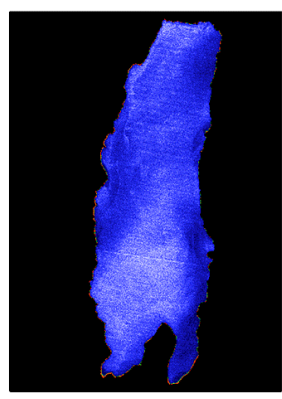

RD: $\quad 03.04 .2000$

TD: 4 days

MI: $\quad 12 \mathrm{~mm}(\mathrm{~T})$

$\mathrm{IF}_{\text {min }}: 0.020$

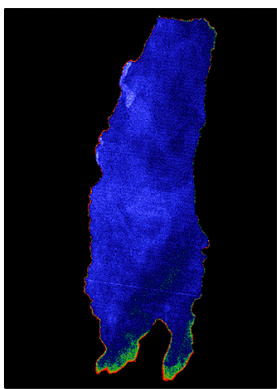

$\mathrm{RD}: \quad 25.08 .2000$

TD: 31 days

Ml: $\quad 39.9 \mathrm{~mm}(\mathrm{~A})$

$\mathrm{IF}_{\min }:-0.021$

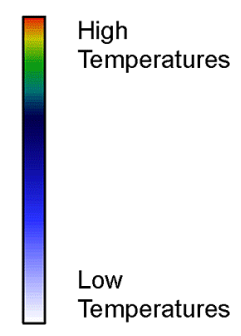

Figure 2. Overview of available SST data for 2000 to 2002, sorted according to the time difference from the last rain occurrence (data show real temperatures and are individually scaled to enhance the contrast). RD: date of image recording; TD: time difference from the end of last rain even; MI: maximum intensity of rain for last rain event, the letter after MI describing rainfall station where the last rain event was recorded; J: Jerusalem; G: Gilgal; A: Amman; T: TRMM; IF $\min =$ minimum IF value calculated). 


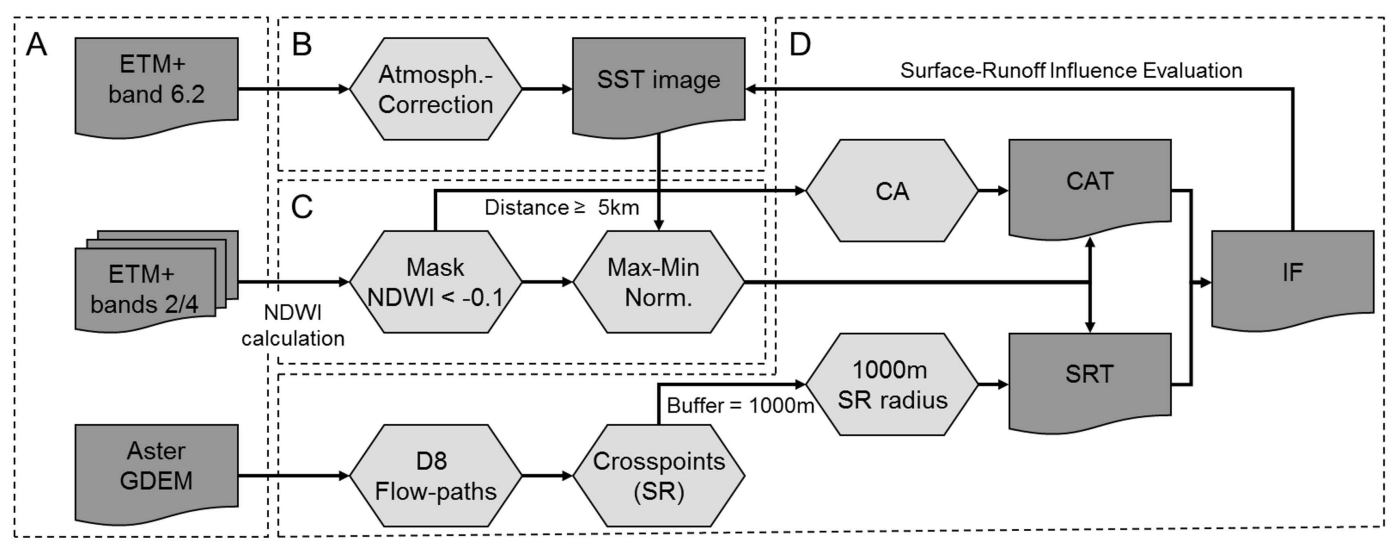

Figure 3. Flowchart of CAT and SRT derivation for surface-runoff influence evaluation; dotted-line boxes: (A) raw data; (B) pre-processing of thermal image; (C) pre-processing for IF calculation; (D) IF calculation.

Seasonal SST variations are addressed by applying a maxmin normalisation in the form of Eq. (5), creating temporally comparable SST images $\left(\mathrm{SST}_{\mathrm{Norm}}\right)$ :

$\mathrm{SST}_{\text {Norm }}=\frac{\mathrm{SST}_{{ }^{\circ} \mathrm{C}}-\mathrm{SST}_{\text {Min }}}{\mathrm{SST}_{\mathrm{Max}}-\mathrm{SST}_{\text {Min }}}$

where $\mathrm{SST}_{\text {Norm }}$ is the normalised SST image, $\mathrm{SST}^{\circ}{ }_{\mathrm{C}}$ is the SST image $\left({ }^{\circ} \mathrm{C}\right), \mathrm{SST}_{\mathrm{Min}}$ is the Global SST Minimum, SST $_{\text {Max }}$ is the Global SST Maximum.

However, the primary aspect is the definition of points at which surface runoff (SR) enters the DS and the central lake area (CA). They form the basis for the development of an exclusion criterion. Each SR originates from crosspoints, where the Dead Sea shore, derived from NDWI, intersects with a surface-runoff path (wadi), and are calculated by using the eight-direction (D8) flow model (Jenson and Domingue, 1988). At each cross point, a $1000 \mathrm{~m}$ radius is taken as investigation area, defining the potential location for SR. In sum, 19 areas along the DS are taken into consideration. Contrastingly, we spatially define the CA by taking a distance of at least $5 \mathrm{~km}$ from the actual shoreline following Stanhill (1990) and Nehorai et al. (2009), who used a distance of $3-5 \mathrm{~km}$ from the shore (Fig. 4).

Applied to the normalised SST images, the 19 SR areas and the CA thus obtained contain a number of pixels $(n)$ representing normalised temperature values. For SR $n$ varies between 1174 and 2520 depending on the changing shape of the shoreline. Regarding CA, $n$ remains almost constant at around 123172 (15 February 2000 - first image of the series) and 123118 (19 November 2002 - last image of the series). Calculating the zonal mean value for each SR and CA results in $k$-representative surface-runoff temperature (SRT) values and one central area temperature (CAT) value. Their difference serves as basis for the evaluation of a surface-runoff influence on the respective image in the form of the influence factor (IF) given in Eq. (6):

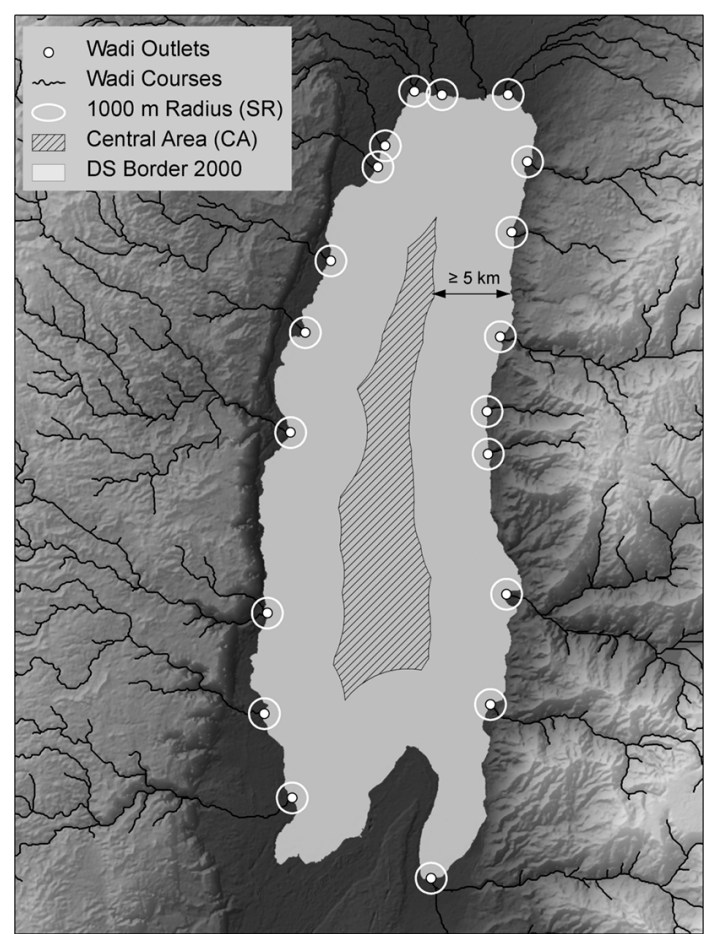

Figure 4. Wadi outlets and investigated outlet radii that are derived using a crosspoints analysis with calculated flow paths and DS boundary and the derived central area of the DS with a minimum distance of $5 \mathrm{~km}$ from any point of the DS boundary.

$$
\begin{aligned}
\mathrm{IF}= & \left(\frac{\sum\left(\mathrm{SRT}_{i j}\left(\mathrm{SST}_{\text {norm }}\right)\right)}{n_{\mathrm{SRT}_{i j}}}\right)_{k}-\left(\frac{\sum\left(\mathrm{CAT}_{i j}\left(\mathrm{SST}_{\text {norm }}\right)\right)}{n_{\mathrm{CAT}_{i j}}}\right) \\
& \mathrm{SR}_{1} \ldots \mathrm{SR}_{k},
\end{aligned}
$$

where $\mathrm{SRT}_{i j}$ is surface-runoff temperature per pixel, $\mathrm{CAT}_{i j}$ is the central area temperature per pixel of the DS, $\mathrm{SST}_{\text {norm }}$ is the max-min normalised SST image from Eq. (5), $n$ is the 
number of pixels within each SR or CA and $k$ is the number of potential surface runoff (SR) points (wadi outlets).

In the case of surface runoff at each wadi outlet, the first term will decrease, while the second term remains constant. It results in negative IF values, which indicate images with surface-runoff influence, and hence provides the criterion needed for evaluation.

\subsection{Evaluation of surface-runoff influence}

In Fig. 5 the IF of each of the 19 wadi outlets of the DS is plotted against the days after a recorded rainfall event for 19 images. Only seven images have positive values (0.0060.020). All of them are the result of a bathymetrical effect with higher SSTs in shallow near-shore areas and lower SSTs in the deeper central DS area. Hence, these images are not influenced by surface runoff. Five images show minimum IF values between -0.318 and -0.104 . These values clearly indicate surface-runoff influence from a statistical perspective. This is validated by the fact that these images are recorded within the first 2 days after the end of a rainfall, most likely causing a subsequent surface-runoff event that is also visible in Fig. 2.

The status of the seven images with only minor negative IF values $(-0.1<x \leq 0)$ remains unclear. We expect that other factors of natural variability (wind, currents, groundwater, etc.) beside surface runoff can lead to slightly lower temperatures, too. Lower temperatures might also result in small negative IF values, which then raises the question of an appropriate threshold by which to decide whether or not a surface-runoff influence exists.

To answer the question of whether negative IF values occur through natural and surface-runoff-independent variability, we calculate the difference between the near-shore temperature (NST) and CAT, analogously to the IF analysis. We spatially define NST areas $(1000 \mathrm{~m}$ radii are maintained to guarantee statistical comparability) to water pixels along the shore that are at a minimum of $2000 \mathrm{~m}$ away from any wadi outlet to exclude possible drifting of surface runoff. The analysis of the temperature variability of 39 NST areas for the 14 images with minimum IF values of $>-0.1$ results in 546 observations. Figure $6 a$ shows the IF values of these observations in intervalls of 0.005 .

It becomes apparent that most of the observations have positive values with a maximum around 0.075 . This clearly shows the bathymetric effect which had been observed previously. However, it also displays the expected minor negative IF values with a minimum of -0.053 in regions where no surface runoff can occur. Hence, it proved that natural variability may cause minor negative values, which can now be quantified as -0.053 . IF values below -0.053 are considered to represent surface-runoff influence and thus should be excluded from groundwater-related studies.

Despite the threshold indication, we would like to draw attention to a number of observations with negative values.

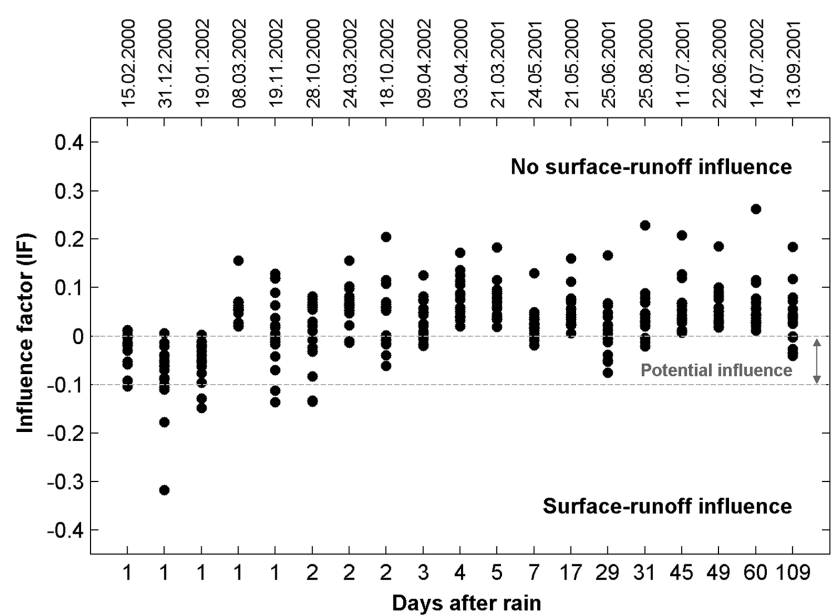

Figure 5. Difference of the means of the normalised temperatures of 19 SRT which represent a surface-runoff area within $1000 \mathrm{~m}$ radius areas at the outlet of wadis and the normalised temperature of the central area (CAT) of the DS. Strong negative values represent a surface-runoff influence while values above 0 indicate no surfacerunoff influence. The range between -0.1 and 0 requires further analysis as both surface runoff and influences from wind, currents, and groundwater can cause minor negative IF values.

Figure $6 \mathrm{~b}$ shows an enlargement of the negative fraction of Fig. 6a, where it becomes clear that the number of observations per class is rather small - ranging from only one to six. Here six different images display these minor negative IF values. Since this number of observations is comparatively small, we presume that not all possible circumstances of natural variability have been covered. Since the circumstances might differ in other study areas, the IF value may change slightly. We suggest taking the -0.053 threshold as an indication and visually reassessing SST images that exhibit an IF value range between -0.053 and 0 to ensure the maximum applicable data basis.

\subsection{Evaluation of influencing time due to surface runoff}

The comparison of sorted SST images after the calculated IF value and available rainfall information from rain stations and TRMM_3B42 indicates an influence due to surface runoff for a minimum of 2 days after the end of the last day of rain (Fig. 2)

Consequently, another two questions arise:

1. Is the 2-day-influencing time period physically feasible and what is the maximum influencing time that can eventuate?

2. Is it appropriate to evaluate SST data suitability for groundwater studies using specific time factors for influencing periods?

We address the first question by determining the maximum physically feasible influencing time period by using Darcy's 


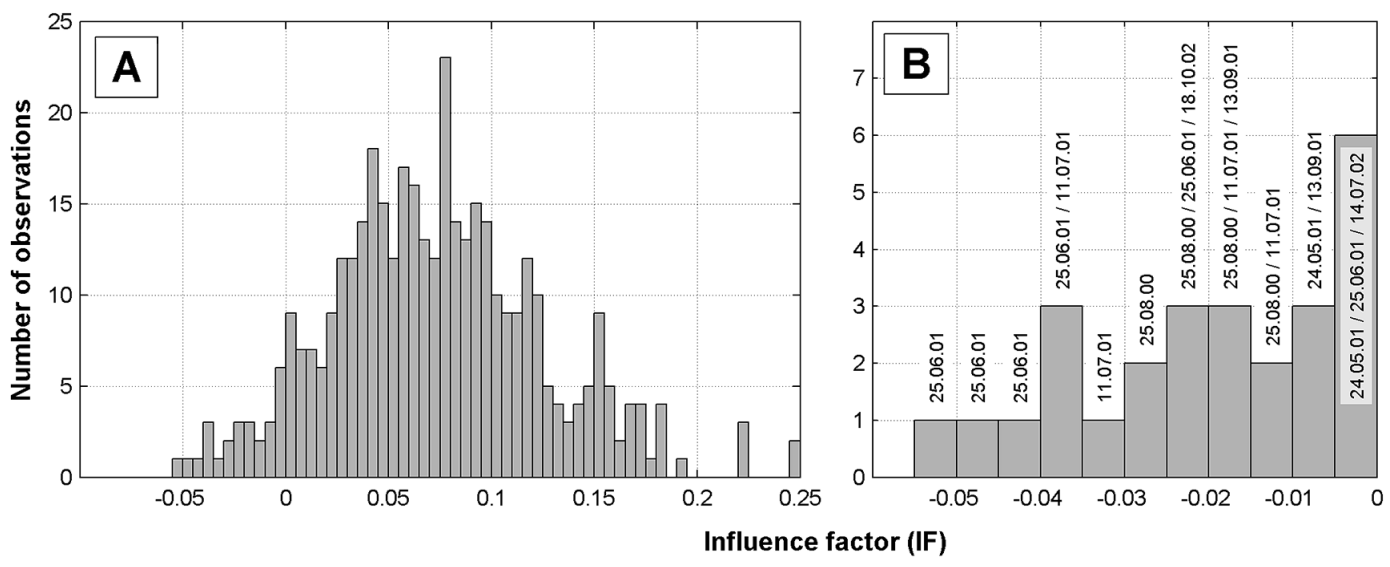

Figure 6. Difference of the means of (a) the normalised temperatures of 39 investigation areas located at least $2000 \mathrm{~m}$ away from wadi outlets with a $1000 \mathrm{~m}$ radius that represents a natural variability and (b) the normalised temperature of the central area (CAT) of the DS. It appears that natural variability can also lead to small negative IF values reaching a minimum value of -0.053 (minimum IF value of the 25 Juni 2001 image), which, hence, represents the threshold for differentiation from surface-runoff-influenced images.

law (Eq. 7). We recall from Sect. 2 that the duration of flash floods in the DS region is at maximum for 6 days for major rain events $(>20 \mathrm{~mm}$ ) (Greenbaum et al., 2006). It is followed by a time-delayed runoff since water-filled pores in wadi courses and fans drain slowly. To quantify the longest possible duration of complete "pore runoff" ( $\left.t_{\text {pore runoff }}\right)$, we assume maximum possible conditions. That means pore space is completely saturated and the applied geometry (volume and cross section of throughflow) represents the largest wadi fan (wadi Darga) along the Dead Sea (see Sects. S5 and S6 in the Supplement for a complete description of input parameters and calculations).

$t_{\text {(pore runoff) }}=V_{\text {total }} \cdot \frac{n_{\text {pores }}}{100} \cdot\left(-k f \cdot \frac{\left(h_{a}-h_{b}\right)}{L} \cdot A\right)^{-1}$,

where $V_{\text {total }}$ is the volume of the alluvial fan $\left(\mathrm{m}^{3}\right), n_{\text {pores }}$ is the porosity of fan material (\%), $k f$ is the hydraulic conductivity of the fan $\left(\mathrm{m} \mathrm{s}^{-1}\right) h_{a}, h_{b}$ is the elevation for the start and end point (m), $L$ is the length between $h_{a}$ and $h_{b}$, and $A$ is a cross-sectional area $\left(\mathrm{m}^{2}\right)$.

Solving Eq. (7) with given parameters results in $98.6 \mathrm{~h}$ (4.11 days), during which stored bank infiltrates from pores of the alluvial fan still drain towards the DS. Adding the maximum flash-flood duration of 6 days returns a maximum influencing time period of 10 days after the end of a rain event during which an impact from surface runoff on the thermal characteristics of the DS is most likely.

Comparing the maximal physically feasible influencing time period of 10 days to Fig. 6 reveals two facts. First of all, the IF method has proven itself valid for identifying surfacerunoff-influenced SST data. Any SST data with strongly negative IF values falls within the maximal physically feasible influencing time period. Secondly, it is shown that a simple criterion such as a time factor for influencing periods, which is also based on additional rain information, is difficult to evaluate when it comes to SST data suitability.

This statement is reasoned by two facts. The SST data from 8 March 2002 were recorded 1 day after the last rainfall. Although the shortness of the previous rain event suggests surface-runoff influence, neither the minimum IF value of 0.020 nor any visual indication points to a surface-runoff influence. Hence, a strict time criterion would exclude this image, even though it is thoroughly applicable.

The second fact relates to the SST data taken on 25 June 2001. The time difference of 29 days from the last rainfall vastly exceeds the maximal physically feasible influencing time period of 10 days and hence suggests no influence through surface runoff due to rainfall. In contrast, the IF value of -0.076 indicates surface-runoff influence. Since rain is very unlikely to fall in this region during June, we assume the occurrence of an external factor such as an artificial water release or dyke failure as described in Closson (2005).

Both examples demonstrate that it is not appropriate to evaluate SST data suitability using certain specific influencing time criteria because unexpected events cannot be anticipated a priori and suitable data is possibly excluded. Hence, we conclude as follows:

1. The previously IF-derived surface-runoff influence threshold of about -0.053 is valid. All SST data with a lower IF value were recorded with a time difference of 2 days from the last rainfall, consequentially falling within the maximal physically feasible influencing time period of 10 days.

2. In terms of groundwater study suitability, SST data should not be evaluated based on auxiliary rainfall data, but on image statistics exclusively. This would only exclude surface-runoff-influenced data and possibly even include relevant data. 
3. For the present study seven SST images are excluded that statistically exhibit surface-runoff influence.

\section{Multi-temporal SST approach amplifying groundwater as cause of thermal anomalies}

The remaining 12 SST images show spatially and thermally persistent groundwater discharge in the form of local thermal anomalies. Considered over time, it is even perceivable that these anomalies exhibit a smaller temporal SST variability. This is due to the fact that temperature-stable groundwater discharge stabilises SST off the discharge location against daily and seasonal temperature variability.

\subsection{Theoretical considerations}

Like in many other regions of the world, groundwater discharge at the DS comprises submarine groundwater discharge with emergence depths down to at least $30 \mathrm{~m}$ below the DS level (Ionescu et al., 2012) but also river-like groundwater discharge from terrestrial springs.

From a theoretical perspective, a prerequisite for the thermal detection of groundwater is the domination of its temperature at the skin layer of the DS. When considering terrestrial springs, the inherited temperature most likely dominates the SST of the water body into which it flows. The reason for this is the density difference between groundwater $\left(1.06-1.19 \mathrm{~g} \mathrm{~cm}^{-3}\right)$ and Dead Sea water $\left(1.24 \mathrm{~g} \mathrm{~cm}^{-3}\right)$; this forms a buoyant layer which is linked to the groundwater discharge. At the surface and the central parts of the buoyant layer, the native temperature remains largely constant while a temperature adaption occurs at small scales along the horizontal and vertical density interface due to friction-induced turbulence (O'Donnell, 1993). The temperature retention and the fact that the horizontal extent of the buoyant layer (discharge plume) has a positive relationship to discharge volume (Ou et al., 2009) leads to the assumption that larger discharge volumes should be thermally identifiable. This effect is even enhanced during winter and summer months, with the maximal potential temperature contrast.

SST stabilisation as a result of submarine spring discharge can therefore be assumed for certain constellations. As it is mainly a function of travelling time $(t)$ from emergence at the seafloor to the sea surface, it can be calculated by using Eq. (7) for round buoyant jets (Lee and Chu, 2003).

$t(z)=z\left(A\left(\frac{\Delta \rho}{\rho_{0}} \frac{\pi}{4} D^{2} \omega_{0}\right)^{\frac{1}{3}} z^{-\frac{1}{3}}\right)^{-1}$,

where $t$ is travelling time (s), $z$ is the depth of emergence (m), $A$ is a specific dimensionless constant with a value of 4.2 following Pantokratoras (2001), $\Delta \rho$ is the difference in density between DS water and groundwater $\left(\mathrm{g} \mathrm{cm}^{-3}\right), \rho_{0}$ is the density of DS $\left(\mathrm{g} \mathrm{cm}^{-3}\right), D$ is the outlet diameter $(\mathrm{m})$, and $\omega_{0}$ is the velocity at outlet $\left(\mathrm{m} \mathrm{s}^{-1}\right)$.
Theoretical considerations with existing constellations (Ionescu et al., 2012) reveal that travelling times remain below $100 \mathrm{~s}$ for small outlets (diameter: $<1 \mathrm{~m}$ ) with a shallow emergence of $<11 \mathrm{~m}$ (see Sect. S7 in the Supplement for details). Because of the short travelling time, we suppose that the native groundwater temperature of discharging water does not completely adapt to ambient temperatures. As the vertical groundwater flow reaches the sea surface, a buoyant layer forms. Its diameter is far greater than the original outlet diameter (Lee and Chu, 2003). Hence, it is conceivable that at least for the mentioned depth and diameter constellation found to exist at the DS (Ionescu et al., 2012), discharging groundwater is thermally identifiable at the sea surface.

\subsection{Multi-temporal SST variability analysis}

Against this promising theoretical background and in context of analysing the temporal SST variability, we calculate the pixel-by-pixel mean (MEAN), standard deviation (SD), maximum temperature (MAX), minimum temperature (MIN), median (MEDIAN), and temperature range (RANGE) of the 12 SST images which are not influenced by surface runoff. The results of the statistical measures are compared to in situ discharge measurements from the Israel Hydrological Service (IHS).

Figure 7 shows a comparison of all applied statistical measures of the multi-temporal SST series and in situ discharge observations for the major spring site Ein Feshkha. The MAX image presents a thoroughly homogenous pattern with just one cooler spot (site A in Fig. 7) at $\sim 28^{\circ} \mathrm{C}$. The spot is directly connected to the shore and spatially coincides with one of the largest terrestrial springs, which has a discharge volume of $0.2 \mathrm{~m}^{3} \mathrm{~s}^{-1}$. Most interestingly, the other two terrestrial springs with elevated discharge volumes of 0.2 and $0.34 \mathrm{~m}^{3} \mathrm{~s}^{-1}$ only cause hardly visible thermal anomalies in the MAX image. The same applies to the MIN-image. Site A is depicted as warmer spot with a temperature of $\sim 21.6^{\circ} \mathrm{C}$, which underlines a thermal stabilisation over ambient SSTs $\left(<20^{\circ} \mathrm{C}\right)$. The difference of $6.2^{\circ} \mathrm{C}$ between the MIN and MAX image of site A indicates an atmospheric influence of $\pm 3^{\circ} \mathrm{C}$ on the discharge temperature. It also reveals that the native temperature of the discharge amounts to $\sim 25^{\circ} \mathrm{C}$. This was verified during a field survey in 2011 by means of physically measured temperatures of $25.2-25.9^{\circ} \mathrm{C}$.

Analogous to the MAX image, the two larger terrestrial springs north of site A are not clearly depicted in the MIN image. Only a fringe is visible (greenish colour in Fig. 7) with similar MIN temperatures of $21.6^{\circ} \mathrm{C}$ as at site A along the shore. This fringe is $\sim{ }^{\circ} \mathrm{C}$ warmer than ambient SST and spatially coincides with all IHS measurement locations of spring discharge independent of discharge volumes. Due to this causality, the fringe most likely points to discharge locations. Special attention is paid to site B. Just like at site $\mathrm{A}$, the MIN temperature is $\sim 21.6^{\circ} \mathrm{C}$, but unlike site $\mathrm{A}$, $\mathrm{B}$ is not connected to the shore. Both facts are evidence of 

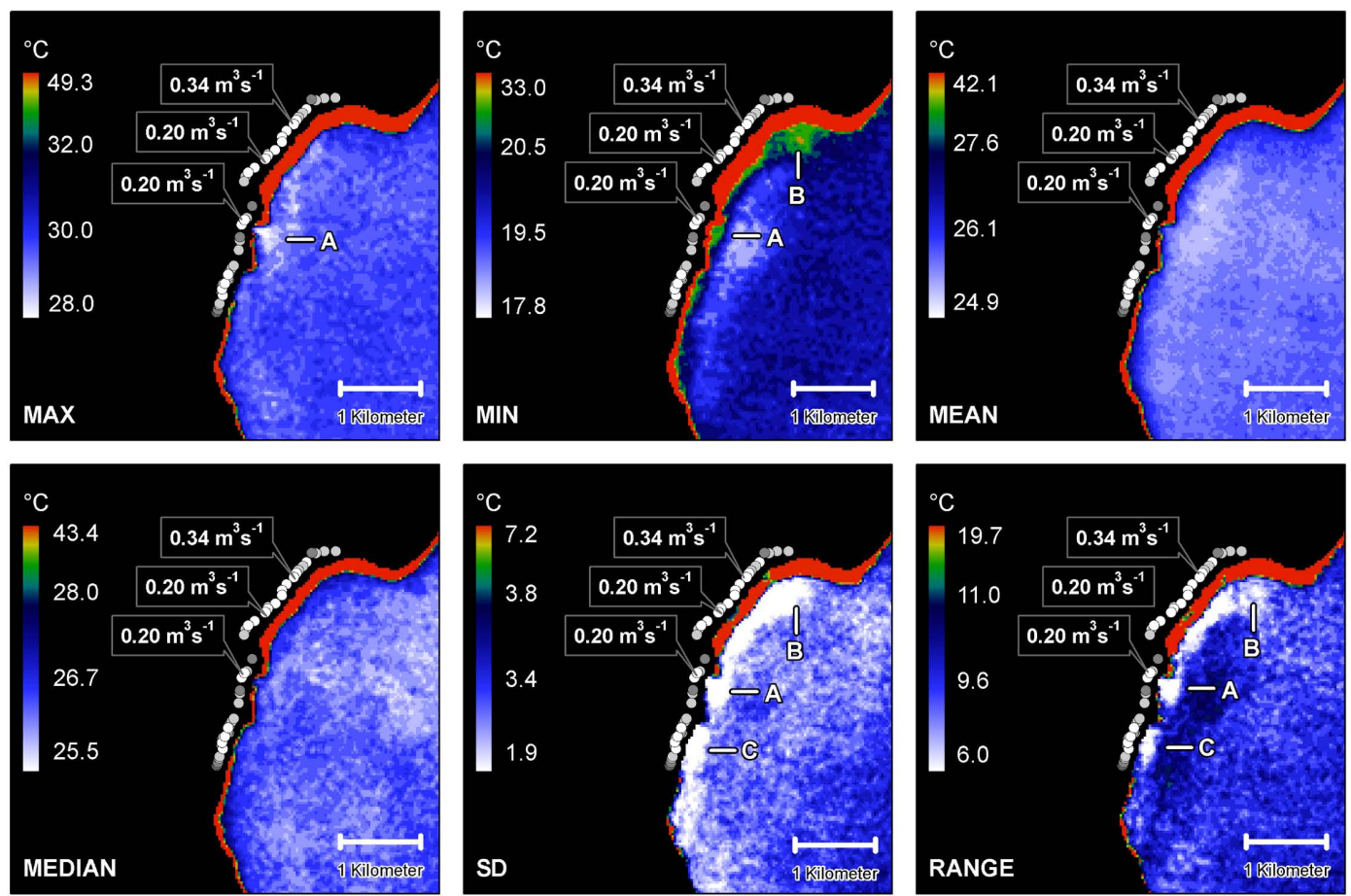

Figure 7. Intercomparison of statistical measures on a per-pixel basis of an SST data series and in situ measured spring discharge volumes from March 2008 (white circles $\geq 0.1 \mathrm{~m}^{3} \mathrm{~s}^{-1}$; light grey circles $0.01-<0.1 \mathrm{~m}^{3} \mathrm{~s}^{-1}$; dark grey circles $<0.01 \mathrm{~m}^{3} \mathrm{~s}^{-1}$ ), showing the example of a major spring site (Ein Feshkha). The tags indicate the discharge volume and the location of the three largest springs at this site; corner coordinates (Lat, Lon) of subsets UL 31.72,35.41 LR 31.66,35.50. Note that the measured spring-discharge locations observed by the IHS are spatially shifted by $200 \mathrm{~m}$ perpendicular to the coast to account for the shoreline retreat between the investigation period (2000-2002) and the time of measurement recording.

a submarine spring with a diameter of some tens of metres similar to that in Fig. 1d. Although this submarine spring cannot be verified with observations made simultaneously to the investigation period, submarine springs in this region have been repeatedly observed by the Israel Hydrological Service (IHS, 2012).

MEAN and MEDIAN images neither show significant zones of discharge nor information on location. Hence, both statistical measures seem not to be suitable for inferring groundwater information from a multi-temporal analysis. In contrast, the SD image clearly proves the already observed terrestrial spring (site A) and the submarine spring (site B) with expected low SD values. Again, it underlines the fact that temperatures of areas which are steadily influenced by temperature-constant groundwater discharge vary insignificantly $\left(1.9-3.0^{\circ} \mathrm{C}\right)$ over ambient SST. Further, it apparently also reflects discharge locations with concentrated but minor discharge volumes $\left(<0.2 \mathrm{~m}^{3} \mathrm{~s}^{-1}\right)$ as low-SD areas spatially coincide with all IHS spring measurement locations (e.g. site C). This suggests that using SD images enables us to provide information on discharge location independent of spring type (terrestrial/submarine) and discharge volumes. Plus, we assume that the areal extent of low SD values forms additively, where single discharge sites or volumes cannot be distinguished but are accumulated to form a connected area instead. The fact that even south of site $\mathrm{C}$, where no IHS measurement locations exist, small SD values occur is striking. While this either represents a so far unknown discharge site, it could also indicate a drawback in terms of a possible false identification of groundwater discharge. The latter could result from a steady deflection through wind or Coriolis forces as described by Ou et al. (2009). Another drawback emerges from a noisy transition zone between the low SD value area and the central parts of the DS.

Low values $\left(<8.5^{\circ} \mathrm{C}\right)$ of the RANGE image indicate the same discharge locations as derived from SD images accompanied by less noise in the transition zone and by distinguishable discharge sites (e.g. A and C). It is striking that the distinguishable discharge locations spatially match the measured discharge locations exactly. This is the case irrespective of discharge volumes (Fig. 7), including the probable submarine spring (site B). Again, it indicates the expected thermal stabilisation through steady groundwater inflow. When comparing the area of low-range values $<8.5^{\circ} \mathrm{C}$ covered (discharge plume) to spatially corresponding accumulated discharge volumes, it even suggests a positive relationship between the discharge plume and the accumulated discharge volume (Sect. S8 in the Supplement). 


\section{Transferability and uncertainty}

The approach presented is based on freely available, largescale satellite data sets and thus, represents a considerable alternative to cost- and labour-intensive field work or airborne campaigns. Only image statistics are incorporated so that auxiliary information, which might be scarce, is not required. The multi-temporal SST data analysis allows inferring reliable groundwater discharge locations and is also independent of discharge intermittency. These aspects make a general application to different environments possible. However, to provide an appropriate basis for a successful application in future studies, we need to discuss related uncertainties in the light of transferability and to advert to further improvements. Hence, the following sections elucidate advantages and uncertainties for each stage of the approach presented.

\subsection{Pre-processing of satellite data}

The method of converting digital numbers (DN) to ground temperatures is widely applied. Different studies were able to successfully derive ground temperatures within the expected failure range (e.g. Barsi et al., 2005; Coll et al., 2010). In order to obtain correct SST, the emissivity value needs to be taken into consideration. We use an emissivity value of 0.97 as a global parameter for saline water in Eq. (2) (Wenyao et al., 1987). Despite the fact that its usage is justified since the majority of water can be considered as high-saline Dead Sea water, a higher emissivity value of 0.99 should be assigned to inflowing, fresher groundwater. This cannot be done a priori, as it is the intention to identify freshwater influences subsequently. Yet the 0.02 difference causes a temperature underestimation of $1-1.5^{\circ} \mathrm{C}$ (Sect. S9 in the Supplement). This means that for a theoretical case of fresher groundwater with a natural temperature of $26^{\circ} \mathrm{C}$, the conversion into SST yields a temperature of $24.5-25.0^{\circ} \mathrm{C}$. If the SST of the Dead Sea has the same temperature naturally as maintained during the conversion from DN into SST, both waters will have identical temperatures in the final SST image. In this case, a differentiation between both waters would be impeded for the single-image case.

The depicted case could occur during the seasons of spring and fall and, hence, may play an influencing role. However, since our approach relies on a multi-temporal analysis, where results of the temperature range in particular are based on winter and summer contrasts, the emissivity uncertainty most likely does not affect the result. It even leads to a better identification of surface runoff. This is accounted for by the underestimated temperature of this freshwater input. In its turn, this artificially enlarges the temperature contrast to the likewise cooler DS water and raises the potential for surfacerunoff identification.

\subsection{Evaluation of surface-runoff influence}

Generally, the presented IF approach is applicable to other semi-arid study areas; however, it may need adjustment. This applies to the IF threshold of -0.053 , which depends on temperature differences between surface runoff and water body. If local temperature gradients differ from the ones presented by the DS example, the IF threshold will need appropriate modification. An appropriate adjustment might also be necessary for the investigation radius of $1000 \mathrm{~m}$ around each surface-runoff spot. The SR radius is sensitive and can influence the result. For the case investigated, the chosen radius provides accurate results but may vary as, e.g., the fluid energy of surface runoff or the density between runoff and lake water differs significantly. If the chosen radii are too large, minor surface runoff will not be detected. By reducing the radii, minor surface runoff from small rainfall events can also be detected. In this case, two issues have to be considered carefully. First, it has to be guaranteed that surface runoff occurs exactly at the defined SR position. And second, if groundwater discharge occurs parallel at wadi outlets, the resulting negative IF values can lead to a misinterpretation of surface runoff.

Likewise, CA has to be defined carefully. Even though, the sensitivity is lower than for SR, the size (area or pixel number) can play a decisive role if the chosen area is very small and simultaneously affected by a secondary influence such as, e.g., currents or large wind effects. This might on the one hand lead to a decrease of the second term in Eq. (6) and on the other hand to erroneous results. To avoid this flaw we suggest considering a large CA if possible.

The mixture of upper and lower water masses in holomictic lakes is another effect that could influence the IF. This entails a decreased CAT value, which in turn increases the IF value. In sum, if rain falls within the overturn period, the IF value approaches a positive value that misleadingly indicates no rain. However, since rain in late summer is usually uncommon, it is less relevant for the present case. For groundwater applications in lakes with dimictic or polymictic regimes on the other hand, reconsideration is required.

\subsection{Multi-temporal SST approach amplifying groundwater as cause of thermal anomalies}

Both SD and RANGE calculations on an SST data series appear to be the best indicators for groundwater discharge and correspond to findings of Tcherepanov et al. (2005). They particularly enhance the small temperature variations that are hardly visible in the MAX and MIN images. Figure 8 highlights the connection. All three example sites show depleted temperature amplitudes throughout the investigation period. The range (standard deviation) values for the example sites vary from $7.1^{\circ} \mathrm{C}\left(2.9^{\circ} \mathrm{C}\right)$ for site A to $9.5^{\circ} \mathrm{C}$ $\left(3.5^{\circ} \mathrm{C}\right)$ and $8.8^{\circ} \mathrm{C}\left(3.3^{\circ} \mathrm{C}\right)$ for sites $\mathrm{B}$ and $\mathrm{C}$, respectively. 


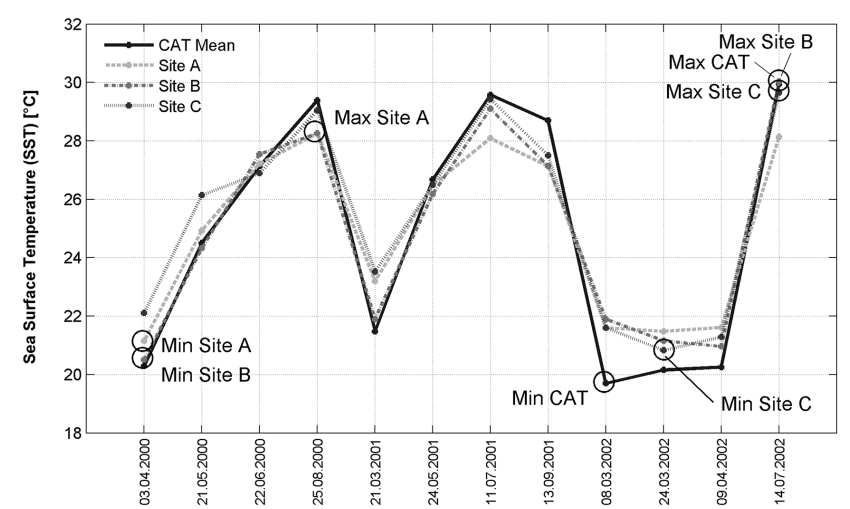

Figure 8. SST over time for sites $\mathrm{A}-\mathrm{C}$ and the mean value of the central area (CAT) as reference. The respective minimum and maximum values of each site are circled.

The corresponding values for the central area amount to $10.5^{\circ} \mathrm{C}\left(4.2^{\circ} \mathrm{C}\right)$.

On the one hand, the constant depletion of SST amplitudes of the example sites confirms the steady and governing influence of groundwater on the SST. It should be assumed that further SST influencing factors such as micrometeorology or water circulation also play a noticeable role. As both are spatially and temporarily inconstant, at least for the DS (Hecht and Gertman, 2003), the influence is different for individual data and should therefore not affect the result dominantly. SSTs are also subject to bathymetry and sensible or latent heat fluxes, which are factors persistently present. However, sensible/latent heat flux is a global parameter that affects the entire sea surface and thus cannot influence the identification of groundwater (Fairall et al., 1996). If bathymetry was the governing force, the SST of the example sites would exceed the SST values of the central area by trend. In fact, this only occurs on site $B$ at the end of the investigation period. For the special case of site B (submarine discharge), it is open to interpretation whether the influence decreases over time or not. This could indicate a dwindling of the discharge volume during summer that consequentially has less effect on the SST at that site.

On the other hand and against the background of identified temperatures at discharge locations, the differently depleted SST amplitudes of the example sites suggest a slower adaption of the native groundwater temperature to ambient Dead Sea temperatures for large discharge volumes due to mixing. In turn, the longer adaption time results in a larger spatial thermal stabilisation (discharge plume). The spatial horizontal dimensions of the discharge plumes roughly correspond to the discharge volumes following a linear relationship between both as presented by Ou et al. (2009), among others, for river discharge.

These aspects need to be considered if the approach presented is to be applied to other areas and environments. However, the general suitability was already proven for the entire coastline of the Dead Sea (Mallast et al., 2013) and also for a rather humid karst environment at Cabbé on the Mediterranean Sea (Schubert et al., 2014). Particularity the latter points to further improvement with regard to the influence of geological-background-constrained discharge behaviour, which may result in low- to high-flow stages. Based upon this aspect, the investigation periods might need to be restricted to high-stage flow periods during which the groundwatercaused SST anomaly is maximally developed.

Other effects, such as wind-induced currents and their spatial distribution, local upwelling phenomena, or tidal influence, did not play a role for the investigation areas presented or mentioned. However, they all have a spatio-temporal effect on the SST distribution and likewise on the applicability of the approach presented. Hence, if investigation areas comprise these influential factors, further investigations and possible adaptions will most likely be required.

\section{Conclusions}

The complicated tasks of gaining information on groundwater discharge over large temporal and spatial scales by conventional means (IAEA, 2007) can be facilitated by thermal remote sensing (Meijerink et al., 2007). In this context, the study presents a multi-temporal SST data approach to identify groundwater discharge locations based on thermal satellite data from Landsat ETM+. Integrated into the approach is the development of an influence factor that autonomously identifies surface-runoff-influenced SST data to avoid skewed results. The multi-temporal, pixel-based analysis of surface-runoff-unaffected SST data reveals the applicability of statistical measures to identify groundwater discharge locations, validated through in situ measurements of the Israel Hydrological Service (IHS) of spring discharge. Based on the analysis, we conclude that:

1. Surface runoff causes similar thermal anomalies to groundwater discharge and needs to be excluded to avoid skewed groundwater-related results.

2. The IF represents a remarkable and autonomously operating alternative to identifying surface-runoff influence in contrast to the utilisation of a time difference criterion based on auxiliary rainfall data; the latter is mostly not capable of adequately reflecting high spatio-temporal variability of rainfall fields in (semi-) arid areas.

3. It was shown that when range and standard deviation per pixel on a SST data series is calculated, groundwater discharge locations independent of spring type (submarine and terrestrial) can be identified. These could be verified by in situ spring discharge measurements of the Israel Hydrological Service. 
4. Considering the distinguishability of low RANGE values to reflect groundwater discharge plumes, (see RANGE image in Fig. 7), it is suggested that the horizontal discharge plume area has a positive relationship to measured discharge volumes, similar to that identified for river discharge by Ou et al. (2009).

The study presented can be used as a blueprint to identify groundwater discharge locations and possibly discharge volumes based on multi-temporal SST data in (semi-)arid environments. Above all, the free-of-charge Landsat data set represents an interesting and valuable alternative to costintensive field work and thermal airborne campaigns and provides information on discharge over large spatial scales which is otherwise complicated to obtain by conventional means (IAEA, 2007). Although not investigated during the present study, the temporal scale can also be used when the total available Landsat thermal data set (1984-today) is used. This in turn would provide valuable insights into climate change, in regard to which the need for water and a proper groundwater management for especially (semi-) arid environments is a subject of discussion.

The proposed approach is not only restricted to limnic environments, but can also be applied to marine environments. Besides a sufficient temperature contrast, an important and so far unmentioned prerequisite for the application of thermal remote sensing data appears to be the density difference between groundwater and the water of the lake or ocean into which it flows. As already pointed out, the density gradient is large for the present case of the DS and most likely alleviates the remotely sensed detection of groundwater. In all cases where groundwater shows a lower density and a temperature contrast compared to the inflowing water body, remotely sensed thermal detection should be feasible. This might also be the case for other climate zones where future research will elucidate individual impacts of, e.g., perennial rivers, tides, and bathymetry. We furthermore recommend a serious consideration of surface runoff as an additional SST pattern anomaly as it influences genuine groundwater results. This accounts for mono- and multi-temporal studies and is also platform independent.

\section{The Supplement related to this article is available online at doi:10.5194/hess-18-2773-2014-supplement.}

Acknowledgements. The study was carried out as part of the BMBF-funded project SUMAR (grant code: 02WM0848). Jan Friesen acknowledges support from the IWAS project (grant code: 02WM1027). We are greatly indebted to Gavriel Weinberger and Udi Galili from the Israel Hydrological Service for providing data on spring discharge, to the Israel National Park Authority and their Ein Feshkha-Kane team who supported us tremendously during field trips, and to John Laronne and his group for remarkable assistance during the investigations. Moreover, this work was supported by Helmholtz Impulse and Networking Fund through the Helmholtz Interdisciplinary Graduate School for Environmental Research (HIGRADE). The authors are grateful to two anonymous reviewers for their helpful comments that significantly improved the manuscript.

The service charges for this open access publication have been covered by a Research Centre of the Helmholtz Association.

Edited by: A. Ghadouani

\section{References}

Arnau, P., Liquete, C., and Canals, M.: River Mouth Plume Events and their Dispersal in the Northwestern Mediterranean Sea, Oceanography, 17, 22-31, 2004.

Ayalon, A., Bar-Matthews, M., and Sass, E.: Rainfall-recharge relationships within a karstic terrain in the Eastern Mediterranean semi-arid region, Israel: [delta] 180 and [delta]D characteristics, J. Hydrol., 207, 18-31, doi:10.1016/s0022-1694(98)00119$\mathrm{x}, 1998$.

Baban, S. M. J.: Detecting and evaluating the influence of water depth, volume and altitude on the variations in the surface temperature of lakes using Landsat imagery, Int. J. Remote Sens., 14, 2747-2758, 1993.

Banks, W. S. L., Paylor, R. L., and Hughes, W. B.: Using Thermal-Infrared Imagery to Delineate Ground-Water Discharged, Ground Water, 34, 434-443, doi:10.1111/j.17456584.1996.tb02024.x, 1996.

Barsi, J. A., Schott, J. R., Palluconi, F. D., and Hook, S. J.: Validation of a web-based atmospheric correction tool for single thermal band instruments, Proc. SPIE, 5882, 1-7, 2005.

Chander, G., Markham, B. L., and Helder, D. L.: Summary of current radiometric calibration coefficients for Landsat MSS, TM, ETM+, and EO-1 ALI sensors, Remote Sens. Environ., 113, 893-903, doi:10.1016/j.rse.2009.01.007, 2009.

Closson, D.: Structural control of sinkholes and subsidence hazards along the Jordanian Dead Sea coast, Environ. Geol., 47, 290301, doi:10.1007/s00254-004-1155-4, 2005.

Coll, C., Galve, J. M., Sanchez, J. M., and Caselles, V.: Validation of Landsat-7/ETM+ Thermal-Band Calibration and Atmospheric Correction With Ground-Based Measurements, IEEE T. Geosci. Remote, 48, 547-555, doi:10.1109/tgrs.2009.2024934, 2010.

Danielescu, S., MacQuarrie, K. T. B., and Faux, R. N.: The integration of thermal infrared imaging, discharge measurements and numerical simulation to quantify the relative contributions of freshwater inflows to small estuaries in Atlantic Canada, Hydrol. Process., 23, 2847-2859, doi:10.1002/hyp.7383, 2009.

Donlon, C. J., Minnett, P. J., Gentemann, C., Nightingale, T. J., Barton, I. J., Ward, B., and Murray, M. J.: Toward Improved Validation of Satellite Sea Surface Skin Temperature Measurements for Climate Research, J. Climate, 15, 353-369, doi:10.1175/15200442(2002)015<0353:TIVOSS>2.0.CO;2, 2002.

Emery, W. J., Castro, S., Wick, G. A., Schluessel, P., and Donlon, C.: Estimating Sea Surface Temperature from Infrared Satellite and In Situ Temperature Data, B. Am. Meteorol. Soc., 82, 2773-2785, doi:10.1175/15200477(2001)082<2773:ESSTFI>2.3.CO;2, 2001. 
Fairall, C. W., Bradley, E. F., Godfrey, J. S., Wick, G. A., Edson, J. B., and Young, G. S.: Cool-skin and warm-layer effects on sea surface temperature, J. Geophys. Res., 101, 1295-1308, doi:10.1029/95jc03190, 1996.

Gavrieli, I., Yechieli, Y., Halicz, L., Spiro, B., Bein, A., and Efron, D.: The sulfur system in anoxic subsurface brines and its implication in brine evolutionary pathways: the Ca-chloride brines in the Dead Sea area, Earth Planet. Sc. Lett., 186, 199-213, doi:10.1016/s0012-821x(01)00247-3, 2001.

Gertman, I. and Hecht, A.: The Dead Sea hydrography from 1992 to 2000, J. Mar. Syst., 35, 169-181, doi:10.1016/S09247963(02)00079-9, 2002.

Greenbaum, N., Ben-Zvi, A., Haviv, I., and Enzel, Y.: The hydrology and paleohydrology of the Dead Sea tributaries, in: New Frontiers in the Dead Sea Paleoenvironmental Research, edited by: Enzel, Y., Agnon, A., and Stein, M., The Geolgical Society of America, Boulder, CO, USA, 63-93, 2006.

Guttman, Y.: Hydrogeology of the Eastern Aquifer in the Judea Hills and Jordan Valley, Mekorot, 83 pp., 2000.

Hall, J. K.: Bathymetric Chart of the Dead Sea, Scale 1: 100000 , prepared for the International Symposium on Rift Zones of the Earth, the Dead Sea, Jerusalem, 1979.

Hecht, A. and Gertman, I.: Dead Sea Meterological Climate, in: Biodiversity of Cyanoprocaryotes, Algae and Fungi of Israel Fungal Life in the Dead Sea, edited by: Nevo, O., Oren, A., and Wasser, S. P., Haifa, Israel, 68-114, 2003.

Huffman, G., Bolvin, D., Nelkin, E., Wolff, D., Adler, R., Gu, G., Hong, Y., Bowman, K., and Stocker, E.: The TRMM Multisatellite Precipitation Analysis (TMPA): Quasi-Global, Multiyear, Combined-Sensor Precipitation Estimates at Fine Scales, J. Hydrometeorol., 8, 38-55, 2007.

IAEA: Nuclear and isotopic techniques for the characterization of submarine groundwater discharge in coastal zones - Results of a coordinated research project 2001-2006, International Atomic Energy Agency - IAEA, Vienna, Austria, 192 pp., 2007.

IHS: Spring discharge measurements along the Dead Sea, unpublished data, Israel Hydrological Service, Jerusalem, 2012.

Ionescu, D., Siebert, C., Polerecky, L., Munwes, Y. Y., Lott, C., Häusler, S., Bižić-Ionescu, M., Quast, C., Peplies, J., Glöckner, F. O., Ramette, A., Rödiger, T., Dittmar, T., Oren, A., Geyer, S., Stärk, H.-J., Sauter, M., Licha, T., Laronne, J. B., and de Beer, D.: Microbial and Chemical Characterization of Underwater Fresh Water Springs in the Dead Sea, PLoS ONE, 7, e38319, doi:10.1371/journal.pone.0038319, 2012.

Jenson, S. K. and Domingue, J. O.: Extracting Topographic Structure from Digital Elevation Data for Geographic InformationSystem Analysis, Photogramm. Eng. Remote Sens., 54, 15931600, 1988.

Laronne Ben-Itzhak, L. and Gvirtzman, H.: Groundwater flow along and across structural folding: an example from the Judean Desert, Israel, J. Hydrol., 312, 51-69, doi:10.1016/j.jhydrol.2005.02.009, 2005.

Lee, J. H. W. and Chu, V.: Turbulent Jets and Plumes - A Lagrangian Approach Kluwer Academics Publishers, Dordrecht, the Netherlands, 2003.

Lensky, N. G., Dvorkin, Y., Lyakhovsky, V., Gertman, I., and Gavrieli, I.: Water, salt, and energy balances of the Dead Sea, Water Resour. Res., 41, W12418, doi:10.1029/2005wr004084, 2005.
Maimone, M.: Defining and Managing Sustainable Yield. Ground Water, 42, 809-814, doi:10.1111/j.1745-6584.2004.tb02739.x, 2004.

Mallast, U., Gloaguen, R., Geyer, S., Rödiger, T., and Siebert, C.: Derivation of groundwater flow-paths based on semi-automatic extraction of lineaments from remote sensing data, Hydrol. Earth Syst. Sci., 15, 2665-2678, doi:10.5194/hess-15-26652011, 2011.

Mallast, U., Siebert, C., Wagner, B., Sauter, M., Gloaguen, R., Geyer, S., and Merz, R.: Localisation and temporal variability of groundwater discharge into the Dead Sea using thermal satellite data, Environ. Earth Sci., 69, 587-603, doi:10.1007/s12665-0132371-6, 2013.

Mazor, E., Levitte, D., Truesdell, A. H., Healy, J., and Nissenbaum, A.: Mixing models and ionic geothermometers applied to warm (up to $60^{\circ} \mathrm{C}$ ) springs: Jordan Rift Valley, Israel, J. Hydrol., 45, 1-19, doi:10.1016/0022-1694(80)90002-5, 1980.

McFeeters, S. K.: The use of the Normalized Difference Water Index (NDWI) in the delineation of open water features, Int. J. Remote Sens., 17, 1425-1432, doi:10.1080/01431169608948714, 1996.

Meijerink, A. M. J., Bannert, D., Batelaan, O., Lubczynski, M. W., and Pointet, T.: Remote Sensing Applications to Groundwater, IHP-VI, Series on groundwater, 16, United Nations Educational, Scientific and Cultural Organization, Paris, 311 pp., 2007.

Munwes, Y., Laronne, J. B., Geyer, S., Siebert, C., Sauter, M., and Licha, T.: Direct measurement of submarine groundwater spring discharge upwelling into the Dead Sea, IWRM, Karlsruhe, 2010.

Nehorai, R., Lensky, I. M., Lensky, N. G., and Shiff, S.: Remote sensing of the Dead Sea surface temperature, J. Geophys. Res., 114, C05021, doi:10.1029/2008jc005196, 2009.

O'Donnell, J.: Surface fronts in estuaries: A review, Estuaries and Coasts, 16, 12-39, doi:10.2307/1352761, 1993.

Ou, S., Zhang, H., and Wang, D.-X.: Dynamics of the buoyant plume off the Pearl River Estuary in summer, Environ. Fluid Mech., 9, 471-492, doi:10.1007/s10652-009-9146-3, 2009.

Pantokratoras, A.: Effect of ambient temperature on vertical turbulent buoyant water jets, Int. J. Heat Mass Trans., 44, 1889-1898, doi:10.1016/s0017-9310(00)00231-3, 2001.

Piñones, A., Valle-Levinson, A., Narvárez, D. A., Vargas, C. A., Navarrete, S. A., Yuras, G., and Castilla, J. C.: Wind-induced diurnal variability in river plume motion, Estuarine, Coast. Shelf Sci., 65, 513-525, doi:10.1016/j.ecss.2005.06.016, 2005.

Salameh, E.: Water Quality Degradation in Jordan (Impacts on Environment, Economy and Future Generations Resources Base), Friedrich Ebert Stiftung, Royal Society for the Conservation of Nature, Amman, 1996.

Salisbury, J. W. and D'Aria, D. M.: Emissivity of terrestrial materials in the $8-14 \mu \mathrm{m}$ atmospheric window, Remote Sens. Environ., 42, 83-106, 1992.

Schubert, M., Scholten, J., Schmidt, A., Comanducci, J. F., Pham, M. K., Mallast, U., and Knoeller, K.: Submarine Groundwater Discharge at a Single Spot Location: Evaluation of Different Detection Approaches, Water, 6, 584-601, 2014.

Sentlinger, G. I., Hook, S. J., and Laval, B.: Sub-pixel water temperature estimation from thermal-infrared imagery using vectorized lake features, Remote Sens. Environ., 112, 1678-1688, doi:10.1016/j.rse.2007.08.019, 2008. 
Siebert, C., Rödiger, T., Geyer, S., Mallast, U., and Gräbe, A.: Western Dead Sea spring measurements, unpublished data, Helmholtz Centre for Environmental Research GmbH - UFZ, 2013.

Siebert, C., Rödiger, T., Mallast, U., Gräbe, A., Guttman, J., Laronne, J. B., Storz-Peretz, Y., Greenman, A., Salameh, E., Al-Raggad, M., Vachtman, D., Zvi, A. B., Ionescu, D., Brenner, A., Merz, R., and Geyer, S.: Challenges to estimate surface- and groundwater flow in arid regions: The Dead Sea catchment, Sci. Total Environ., 485-486, 828-841, doi:10.1016/j.scitotenv.2014.04.010, 2014.

Stanhill, G.: Changes in the surface temperature of the dead sea and its heat storage, Int. J. Climatol., 10, 519-536, doi:10.1002/joc.3370100508, 1990.

Stanislavsky, E. and Gvirtzman, H.: Basin-scale migration of continental-rift brines: Paleohydrologic modeling of the Dead Sea basin, Geology, 27, 791-794, doi:10.1130/00917613(1999)027<0791:bsmocr>2.3.co;2, 1999.
Tcherepanov, E. N., Zlotnik, V. A., and Henebry, G. M.: Using Landsat thermal imagery and GIS for identification of groundwater discharge into shallow groundwater-dominated lakes, Int. J. Remote Sens., 26, 3649-3661, 2005.

Walker, N. D.: Satellite assessment of Mississippi River plume variability: Causes and predictability, Remote Sens. Environ., 58, 21-35, doi:10.1016/0034-4257(95)00259-6, 1996.

Wenyao, L., Field, R., Gantt, R., and Klemas, V.: Measurement of the surface emissivity of turbid waters, Chinese J. Oceanol. Limnol., 5, 363-369, doi:10.1007/bf02843818, 1987.

Wloczyk, C., Richter, R., Borg, E., and Neubert, W.: Sea and lake surface temperature retrieval from Landsat thermal data in Northern Germany, Int. J. Remote Sens., 27, 2489-2502, doi:10.1080/01431160500300206, 2006.

Yechieli, Y., Shalev, E., Wollman, S., Kiro, Y., and Kafri, U.: Response of the Mediterranean and Dead Sea coastal aquifers to sea level variations, Water Resoures Res., 46, W12550, doi:10.1029/2009wr008708, 2010. 